\title{
Trapping of hydrogen isotopes in radiation defects formed in tungsten by neutron and ion irradiations
}

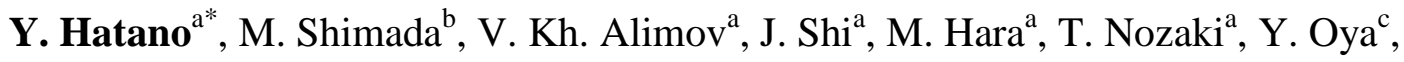

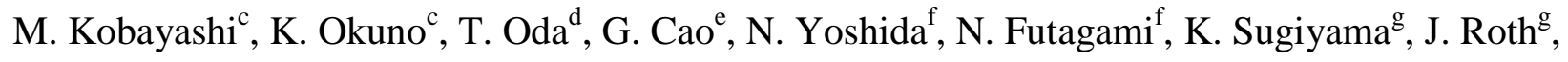

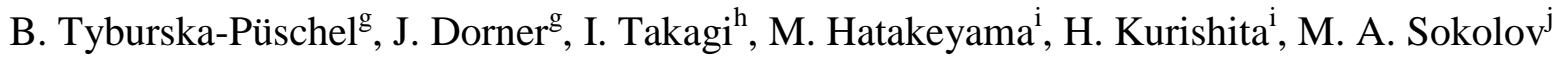 \\ ${ }^{\mathrm{a}}$ Hydrogen Isotope Research Center, University of Toyama, Toyama 930-8555, Japan \\ ${ }^{\mathrm{b}}$ Fusion Safety Program, Idaho National Laboratory, Idaho Falls, ID 83415, USA \\ ${ }^{\mathrm{c}}$ Faculty of Science, Shizuoka University, Shizuoka 422-8529, Japan \\ ${ }^{\mathrm{d}}$ Department of Nuclear Engineering and Management, The University of Tokyo, Tokyo 113-8656, Japan \\ ${ }^{\mathrm{e}}$ Department of Engineering Physics, The University of Wisconsin, Madison, WI 53706, USA \\ ${ }^{\mathrm{f}}$ Research Institute for Applied Mechanics, Kyushu University, Kasuga 816-8580, Japan \\ ${ }^{\mathrm{g}}$ Max-Planck-Institut für Plasmaphysik, EURATOM Association, D-85748 Garching, Germany \\ ${ }^{\mathrm{h}}$ Department of Nuclear Engineering, Kyoto University, Kyoto 606-8501, Japan \\ institute of Materials Research, Tohoku University, Oarai 311-1313, Japan \\ ${ }^{\mathrm{j} O a k}$ Ridge National Laboratory, Oak Ridge, TN 37831, USA
}

\begin{abstract}
Retention of D in neutron-irradiated $\mathrm{W}$ and desorption were examined after plasma exposure at $773 \mathrm{~K}$. Deuterium was accumulated at a relatively high concentration up to a large depth of 50-100 $\mu \mathrm{m}$ due to the trapping effects of defects uniformly induced in the bulk. A significant $\mathrm{D}$ release in a vacuum continued to temperatures $\geq 1173 \mathrm{~K}$ because of the small effective diffusion coefficient and the long diffusion distance. Exposure of ion-irradiated $\mathrm{W}$ to $\mathrm{D}_{2}$ gas showed a clear correlation between concentrations of trapped and solute D as determined by the trapping-detrapping equilibrium. These observations indicated that the accumulation of tritium in high concentrations is possible even at high temperatures if the concentration of solute tritium is high, and baking at moderate temperatures is ineffective for removal of tritium deeply penetrating into the bulk. Nevertheless, clear enhancement of D release was observed under the presence of solute $\mathrm{H}$.
\end{abstract}




\section{PACS}

28.52.Fa, 61.80.Hg, 61.82.Bg, 67.63.-r

\section{PSI-20 Keywords}

Tungsten, Neutron damage, Trapping, Tritium inventory, Thermal desorption

\section{Corresponding Author Address}

Yuji Hatano

Hydrogen Isotope Research Center, University of Toyama, Toyama 930-8555, Japan

\section{Corresponding Author e-mail}

hatano@ctg.u-toyama.ac.jp

Presenting Author

Yuji Hatano

\section{Presenting Author e-mail}

hatano@ctg.u-toyama.ac.jp 


\section{Introduction}

Tungsten (W) and its alloys are primary candidates for plasma-facing materials (PFMs) in fusion reactors. As PFMs, W materials will be exposed to the high fluxes of deuterium (D) and tritium (T) particles under irradiation of $14 \mathrm{MeV}$ neutrons (n). Defects created by n-irradiation act as traps for hydrogen $(\mathrm{H})$ isotopes, and hence the $\mathrm{T}$ inventory in $\mathrm{n}$-irradiated $\mathrm{W}$ materials is an important issue when assessing the safety of fusion reactors.

The effects of displacement damage on the retention of $\mathrm{H}$ isotopes in $\mathrm{W}$ have been simulated using ion-irradiation techniques [1-10]. In such studies, specimens of W were irradiated with various types of high-energy ions $(\sim \mathrm{MeV})$ to moderate damage levels $(\sim$ a few dpa) and exposed to relatively low energy, high-flux (eV-keV, $\left.10^{20}-10^{24} \mathrm{~m}^{-2} \mathrm{~s}^{-1}\right) \mathrm{D}$ plasma or ions. A significant increase in D retention due to irradiation was observed, and the fraction of trapped $\mathrm{D}$ atoms to $\mathrm{W}$ atoms, $F_{\mathrm{D} \text {-trap, }}$ in the damaged zones was ca. 1 at. $\%$ at exposure temperature $T_{\mathrm{ex}} \leq 500 \mathrm{~K}$. There is, however, disagreements regarding $F_{\mathrm{D} \text {-trap }}$ at higher temperatures. Wampler and Doerner [3] reported that $F_{\text {D-trap }}$ at $0.6 \mathrm{dpa}$ and $T_{\mathrm{ex}}=773 \mathrm{~K}$ was ca. 0.01 at.\%, whereas that at $473 \mathrm{~K}$ was $0.2-0.6$ at.\%. Ogorodnikova et al. [5] and Tyburska et al. [6] irradiated relatively thin $\mathrm{W}$ foils and exposed the opposite side to D plasma to separate the effects of radiation damage and plasma-induced defects. They also observed a sharp reduction in $F_{\text {D-trap }}$ with an increase in $T_{\text {ex }} ; F_{\text {D-trap }}$ was 0.003 at.\% at $775 \mathrm{~K}$ [6]. On the other hand, Wright et al. [4] observed an accumulation of D up to $F_{\mathrm{D}-\text { trap }}=0.3-0.5$ at.\% even at $950 \mathrm{~K}$. The mechanisms underlying such discrepancy are still unclear. Tsukatani et al. [7] reported that D trapped by defects created with $300 \mathrm{keV} \mathrm{H}^{-}$ions was released at 523-623 K. However, the thickness of the damaged zone was $1.4 \mu \mathrm{m}$. The release of $\mathrm{H}$ isotopes from thick damaged $\mathrm{W}$ materials has not been examined to date.

In previous papers, the authors have investigated $\mathrm{D}$ retention in $\mathrm{W}$ irradiated with neutrons in a fission reactor [11-15]. First, W specimens irradiated to 0.025 dpa was exposed to high-flux D plasma at $473 \mathrm{~K}$, and then the retention and detrapping of D were examined by thermal desorption spectroscopy (TDS) [11-14]. The D retention in n-irradiated specimen was clearly higher than that in non-irradiated specimen. In addition, the release of D from the former continued to $1173 \mathrm{~K}$, while that from the latter was completed at $673 \mathrm{~K}$. These observations indicated the formation of strong traps by n-irradiation. The temperature dependence of $F_{\mathrm{D}-\text { trap }}$ 
near the surfaces was also examined after exposure to D plasma at 373, 473 and $773 \mathrm{~K}$ by nuclear reaction analysis (NRA) [15]. The values of $F_{\mathrm{D} \text {-trap }}$ showed no significant dependence on $T_{\mathrm{ex}}$, and they were $0.1-0.3$ at.\% at all $T_{\text {ex }}$ examined. Such dependence of $F_{\text {D-trap }}$ on $T_{\text {ex }}$ was similar to the observation of Wright et al. [4] but clearly inconsistent with those reported in [3,5,6]. In addition, the penetration depth of $\mathrm{D}$ at $T_{\mathrm{ex}}=773 \mathrm{~K}$ was larger than the detection depth of NRA $(\sim 5 \mu \mathrm{m}$ in the previous paper), and hence $\mathrm{D}$ retention at $773 \mathrm{~K}$ has not been clarified.

In this study, thermal desorption of $\mathrm{D}$ from $\mathrm{n}$-irradiated $\mathrm{W}$ specimen ( $0.025 \mathrm{dpa})$ exposed to D plasma at $773 \mathrm{~K}$ was examined to understand the retention and release of D after plasma exposure at high temperature. The efficiency of $\mathrm{T}$ removal by heat treatments was discussed on the basis of the observed D release behavior. The correlation between the concentrations of trapped D and solute D was also examined in this study using ion-irradiated specimens and gasabsorption technique in order to gain an understanding of the mechanisms underlying the abovementioned discrepancy in $F_{\mathrm{D} \text {-trap }}$ at high temperatures. Because a far higher damage level is expected in a demonstration power plant (DEMO), D retention in $\mathrm{W}$ specimens irradiated to 50 dpa with $\mathrm{W}$ ions was also examined.

\section{Model}

In this paper, the enthalpy difference between $\mathrm{H}$ in a solid solution state and in a trapped state is described as $E_{\text {bin }}$ and is called as the "binding energy". The activation energy for detrapping is denoted as $E_{\text {det }}$. The value of $E_{\text {det }}-E_{\text {bin }}$ should be comparable with that of $E_{\mathrm{d}}$ where $E_{\mathrm{d}}$ is the activation energy for $\mathrm{H}$ diffusion in a normal bcc lattice of $\mathrm{W}$ without traps (see, for example, Fig. 2 in [16]).

The fraction of occupied traps, $\theta_{\mathrm{t}}$, at temperature $T$ is expressed as

$$
\theta_{\mathrm{l}} /\left(1-\theta_{\mathrm{t}}\right)=\theta_{\mathrm{L}} \exp \left(E_{\mathrm{bin}} / k T\right)
$$

where $\theta_{\mathrm{L}}$ is the fraction of occupied interstitial sites and $k$ is the Boltzmann constant [16]. As the heat of solution $E_{\mathrm{S}}$ of $\mathrm{H}$ in W is a large positive value, $\theta_{\mathrm{L}} \ll<1$ in $\mathrm{W}$ even under exposure to highflux $\mathrm{H}$ plasma. Nevertheless, $\theta_{\mathrm{t}}$ could be close to unity if $E_{\mathrm{bin}} / k T$ is large enough. In other words, traps are fully occupied by $\mathrm{H}$ at low temperatures. At temperatures sufficiently high to activate 
the detrapping process, trapping-detrapping equilibrium can be attained, and $\theta_{\mathrm{t}}$ varies with the $\mathrm{H}$ concentration in a solid solution state $C_{\mathrm{SS}}$ being proportional to $\theta_{\mathrm{L}}\left(C_{\mathrm{SS}}=C_{\mathrm{L}} \theta_{\mathrm{L}}\right.$ where $C_{\mathrm{L}}$ is the concentration of interstitial sites). Under exposure to $\mathrm{H}$ plasma, $C_{\mathrm{SS}}$ is determined by the balance between penetrating flux $\alpha \phi_{\text {in }}$ and recycling flux $\phi_{\mathrm{r}}$ of H. Here, $\alpha$ is the sticking coefficient and $\phi_{\mathrm{in}}$ is the incident flux. In the first approximation, $\alpha \phi_{\mathrm{in}}=\phi_{\mathrm{r}}=k_{\mathrm{r}} C_{\mathrm{SS}-\mathrm{S}}{ }^{2}$ in a steady state where $C_{\mathrm{SS}-\mathrm{S}}$ is the concentration of solute $\mathrm{H}$ beneath the surface and $k_{\mathrm{r}}$ is the recombination rate constant. Hence, $C_{\mathrm{SS}-\mathrm{S}}=\left(\alpha \phi_{\mathrm{in}} / k_{\mathrm{r}}\right)^{1 / 2}$. When specimens are exposed to $\mathrm{H}_{2}$ gas, $C_{\mathrm{SS}}$ is determined by Sieverts law: $C_{\mathrm{SS}}=k_{0} \exp \left(-E_{\mathrm{S}} / k T\right) P^{1 / 2}$ where $k_{0}$ is the solubility constant and $P$ is the $\mathrm{H}_{2}$ pressure. Because $k_{\mathrm{r}}$ sensitively depends on surface conditions such as impurity coverage, exposure to gas is generally better at controlling $C_{\mathrm{SS}}$.

Penetration of $\mathrm{H}$ into irradiated $\mathrm{W}$ has been discussed by Wampler and Doerner [3] and Whyte [17]. If an irradiated specimen is exposed to $\mathrm{H}$ plasma (or $\mathrm{H}_{2}$ gas) at $E_{\mathrm{bin}} / k T>1, \mathrm{H}$ that has entered into the specimen immediately becomes trapped when it encounters an unoccupied trap. Under such conditions, a clear interface between filled zone $\left(\theta_{\mathrm{t}} \approx 1\right)$ and empty zone $\left(\theta_{\mathrm{t}} \approx 0\right)$ can be observed as shown in Fig. 1 of [18]. The velocity of the interface is

$$
\mathrm{d} x / \mathrm{d} t=D_{\mathrm{L}} C_{\mathrm{SS}-\mathrm{S}} /\left(x C_{\mathrm{t}}\right)
$$

where $x$ is the depth from the surface, $t$ is time, $D_{\mathrm{L}}$ is the diffusion coefficient of $\mathrm{H}$ in a normal lattice of $\mathrm{W}$ and $C_{\mathrm{t}}$ is the trap concentration [3]. In the filled zone, the diffusion of solute $\mathrm{H}$ is not significantly affected by traps because almost all the traps are already occupied.

If plasma-exposed specimens are heated in a vacuum for thermal-desorption measurements or T removal, $C_{\mathrm{SS}}$ in the near-surface region drops quickly. Consequently, $\theta_{\mathrm{t}}$ in the near-surface region also decreases as expected from Eq. (1). At $\theta_{\mathrm{t}}<1$, the diffusion process of $\mathrm{H}$ is strongly affected by traps. According to Oriani [19], the effective diffusion coefficient $D_{\text {eff }}$ under trapping effects is $D_{\text {eff }}=D_{\mathrm{L}} /\left(1+\exp \left(E_{\mathrm{bin}} / k T\right) C_{\mathrm{t}} / C_{\mathrm{L}}\right)$. Here, it is worthwhile to evaluate the possible effects of traps under typical conditions. According to Frauenfelder [20], $D_{\mathrm{L}}$ at 673 $\mathrm{K}$ is evaluated to be $5 \times 10^{-10} \mathrm{~m}^{2} \mathrm{~s}^{-1}$. If $C_{\mathrm{t}}=1.3 \times 10^{26} \mathrm{~m}^{-3}(0.2$ at. $\%$ in the fraction to $\mathrm{W}$ atoms $)$ and $E_{\text {bin }}=1.4 \mathrm{eV}, D_{\text {eff }}$ in the near-surface region is calculated to be $D_{\text {eff }}=5 \times 10^{-17} \mathrm{~m}^{2} \mathrm{~s}^{-1}$. Such a 
small $D_{\text {eff }}$ in the near-surface region can retard the release of $\mathrm{H}$ from the bulk of irradiated specimens.

In this study, the release of $\mathrm{H}$ from irradiated $\mathrm{W}$ was evaluated numerically using the TMAP4 program [21]. In the evaluation, the value of $D_{\mathrm{L}}$ reported by Frauenfelder [20] was employed. The surface concentration of $\mathrm{H}$ was maintained at zero; the rates of surface reactions were assumed to be sufficiently high in comparison with the diffusion process under trapping effects. Annihilation of defects during heating was not taken into account.

\section{Experimental procedures}

\subsection{Neutron irradiation and measurement of thermal desorption spectrum}

The detailed experimental procedures for n-irradiated specimens are described elsewhere $[11,14]$, and so only a brief description is given here. Disk-type specimens of $\mathrm{W}(\phi 6 \mathrm{~mm} \times 0.2$ $\mathrm{mm}, 99.99 \%$ purity) were irradiated by neutrons to $0.025 \mathrm{dpa}$ in the High Flux Isotope Reactor (HFIR) at Oak Ridge National Laboratory at a coolant temperature of ca. $323 \mathrm{~K}$. The n-irradiated specimens were then exposed to high-flux deuterium plasma at $773 \mathrm{~K}$ up to $(5-7) \times 10^{25} \mathrm{D} \mathrm{m}^{-2}$ in a linear plasma machine called the Tritium Plasma Experiment (TPE) at Idaho National Laboratory. The flux and incident energy was $(5-7) \times 10^{21} \mathrm{D} \mathrm{m}^{-2} \mathrm{~s}^{-1}$ and $100 \mathrm{eV}$, respectively. Deuterium retention and $E_{\mathrm{det}}$ were examined by using thermal desorption spectroscopy (TDS). The rate of the temperature ramp was $0.167 \mathrm{~K} \mathrm{~s}^{-1}\left(10 \mathrm{~K} \mathrm{~min}^{-1}\right)$.

\subsection{Irradiation of W self-ions and D measurements}

Because the damage rate by neutron irradiation is relatively small, the effects of a higher dose of irradiation were studied by damaging specimens with $\mathrm{W}$ ions. Irradiation for a moderate damage level (0.5 dpa) was carried out with $20 \mathrm{MeV}$ W ions at room temperature at the MaxPlanck-Institut für Plasmaphysik to a fluence of $8 \times 10^{17} \mathrm{~W} \mathrm{~m}^{-2}$. Plates of recrystallized $\mathrm{W}$ and ITER-grade W $(10 \times 10 \times 2 \mathrm{~mm})$ were used. Details of these specimens are described elsewhere [18]. Irradiation up to higher damage levels ( 0.3 to $50 \mathrm{dpa}$ ) was carried out with $4.8 \mathrm{MeV} \mathrm{W}$ ions at room temperature and $573 \mathrm{~K}$ using a tandem accelerator at the Quantum Science and Engineering Center, Kyoto University. Disk-type W specimens similar to those used in nirradiation were utilized. The flux of $\mathrm{W}$ ions was $10^{14}-10^{15} \mathrm{~m}^{-2} \mathrm{~s}^{-1}$ depending on the target 
damage level. Damage profiles were evaluated using the SRIM2008 program [22]. The displacement threshold energy of $\mathrm{W}$ was adjusted to $90 \mathrm{eV}$.

To examine the trapping-detrapping equilibrium [Eq. (1)] under controlled $C_{\mathrm{SS}}$, specimens irradiated with $20 \mathrm{MeV}$ W ions were exposed to $\mathrm{D}_{2}$ gas at $673-973 \mathrm{~K}$ for $1-10 \mathrm{~h}$. The specimens were placed in a quartz tube attached to a conventional high-vacuum device described elsewhere [18] and heated from outside using a furnace. The pressure of $\mathrm{D}_{2}$ gas was adjusted to 1.2 and $100 \mathrm{kPa}$. At the end of exposure, the device was quickly evacuated and the specimens were cooled by removing the furnace within 10-30 s [18]. The release of D and effects of coexisting $\mathrm{H}$ were examined by heating D-loaded specimens in a vacuum or under $\mathrm{H}_{2}$ atmosphere $(0.1 \mathrm{MPa})$ at $673 \mathrm{~K}$.

The specimens irradiated with 4.8 MeV W ions were exposed to D neutrals in a DC glow discharge device described elsewhere [18] at a relatively low temperature $(403 \mathrm{~K})$ for $10 \mathrm{~h}$ to examine trap concentrations at high damage levels. Each specimen was placed on a holder serving as an anode. The cathode was a tungsten disk located at a distance of about $100 \mathrm{~mm}$. The pressure of deuterium, discharge voltage and current were $1 \mathrm{~Pa}, 400 \mathrm{~V}$ and $0.18 \mathrm{~A}$, respectively. The specimen was exposed to D neutrals (atoms and molecules), and the total flux was $2 \times 10^{18} \mathrm{D} \mathrm{m}^{-2} \mathrm{~s}^{-1}[18]$.

Depth profiles of D up to $6 \mu \mathrm{m}$ were measured by using NRA. The retention and $E_{\mathrm{det}}$ were measured by TDS. The rate of the temperature ramp was $0.5 \mathrm{~K} \mathrm{~s}^{-1}$.

\section{Results}

\subsection{Thermal desorption of deuterium from neutron-irradiated $\mathrm{W}$}

Fig. 1 shows the TDS spectrum of D from n-irradiated and non-irradiated specimens after exposure to D plasma at $773 \mathrm{~K}$. A significantly large desorption peak of D was observed for a nirradiated specimen in comparison with a non-irradiated one. The $\mathrm{D}$ desorption from the $\mathrm{n}$ irradiated specimen started at $730 \mathrm{~K}$, peaked at $1050 \mathrm{~K}$ and continued to $T \geq 1173 \mathrm{~K}$, while that from non-irradiated specimen was completed at $930 \mathrm{~K}$. The amount of $\mathrm{D}$ retained in the $\mathrm{n}$ irradiated specimen was $6.4 \times 10^{21} \mathrm{D} \mathrm{m}^{-2}$, and that in the non-irradiated one was $1.1 \times 10^{20} \mathrm{D} \mathrm{m}^{-2}$. For comparison, TDS spectrum of $\mathrm{D}$ from the specimen irradiated with $4.8 \mathrm{MeV} \mathrm{W}$ ions to 50 dpa at $573 \mathrm{~K}$ and exposed to D neutrals at $403 \mathrm{~K}$ is also shown in this figure. Desorption started 
at $600 \mathrm{~K}$, peaked at $730 \mathrm{~K}$ and finished at $1050 \mathrm{~K}$. The retention of $\mathrm{D}$ was $3.5 \times 10^{20} \mathrm{D} \mathrm{m}^{-2}$. Both desorption temperature and retention were lower than those for the n-irradiated specimen $(0.025$ dpa) in spite of the far higher damage level. Interestingly, the D retention in the n-irradiated specimen after D plasma exposure at $T_{\mathrm{ex}}=773 \mathrm{~K}\left(6.4 \times 10^{21} \mathrm{D} \mathrm{m}^{-2}\right)$ was significantly larger also than that after plasma exposure at $T_{\mathrm{ex}}=473 \mathrm{~K}\left(2.4 \times 10^{21} \mathrm{D} \mathrm{m}^{-2}\right)$ [11], although Eq. (1) indicates a decrease in $\theta_{\mathrm{t}}$ with an increase in $T_{\mathrm{ex}}$. The larger $\mathrm{D}$ retention in n-irradiated specimen at $T_{\mathrm{ex}}=$ $773 \mathrm{~K}$ was caused by the combination of volumetrically distributed defects created by neutrons and deeper penetration of $\mathrm{D}$ due to high exposure temperature. According to the calculation with the SRIM2008 program, the thickness of damaged zones created by $4.8 \mathrm{MeV}$ W ions was $0.6 \mu \mathrm{m}$. The penetration depth of $\mathrm{D}$ in the n-irradiated specimen at $T_{\mathrm{ex}}=473 \mathrm{~K}$ was ca. $3 \mu \mathrm{m}$ [15]. On the other hand, in the profile after plasma exposure at $773 \mathrm{~K}, F_{\text {D-trap }}$ of $0.1-0.2$ at.\% (i.e., $6.3-12.6 \times$ $10^{25} \mathrm{D} \mathrm{m}^{-3}$ ) extended over the detection range of NRA $(5 \mu \mathrm{m})$ [15]. The penetration depth of D at $T_{\text {ex }}=773 \mathrm{~K}$ was calculated to be $50-100 \mu \mathrm{m}$ as the quotient of the amount of retained D $(6.4 \times$ $\left.10^{21} \mathrm{D} \mathrm{m}^{-2}\right)$ and $\mathrm{D}$ concentration $\left(6.3-12.6 \times 10^{25} \mathrm{D} \mathrm{m}^{-3}\right)$ by assuming that $\mathrm{D}$ concentration was uniform throughout the penetration depth. As shown by numerical evaluation by Whyte [17], deeper penetration of hydrogen isotopes in $\mathrm{n}$-irradiated $\mathrm{W}$ at higher temperatures can have strong impact on tritium retention in a pulse operation machine like ITER.

Eq. (2) can be modified as

$$
C_{\mathrm{SS}-\mathrm{S}}=x^{2} C_{\mathrm{t}} /\left(2 D_{\mathrm{L}} t\right)
$$

Here, the exposure time $t$ was $10 \mathrm{ks}$. By assuming $x=50-100 \mu \mathrm{m}$ and $C_{\mathrm{t}}$ is equal to the abovementioned D concentration $\left(6.3-12.6 \times 10^{25} \mathrm{D} \mathrm{m}^{-3}\right), C_{\mathrm{SS}-\mathrm{S}}$ at $T_{\mathrm{ex}}=773 \mathrm{~K}$ was evaluated with the value of $D_{\mathrm{L}}$ reported in [20] to be $7-54 \times 10^{21} \mathrm{D} \mathrm{m}^{-3}(0.1-1$ at. $\mathrm{ppm})$. Because $C_{\mathrm{SS}-\mathrm{S}}=\left(\alpha \phi_{\mathrm{in}} / k_{\mathrm{r}}\right)^{1 / 2}$, $k_{\mathrm{r}}$ under the present conditions was calculated to be ca. $10^{-24}-10^{-22} \mathrm{~m}^{4} \mathrm{~s}^{-1}$ by assuming $\alpha=1$. These values are in reasonable agreement with those reported by Anderl et al. [23] (see also Fig. 2 in [8]), indicating that the surface conditions of the present specimens were not peculiar.

The result of a simulation run using the TMAP4 program is also shown in Fig. 1. In this simulation, the thickness of the specimen was adjusted to $100 \mu \mathrm{m}$ because $\mathrm{D}$ penetrated up to this depth, as described above. The real specimen thickness was $200 \mu \mathrm{m}$, but the presence of 
remaining $100 \mu \mathrm{m}$ zone without trapped $\mathrm{D}$ was neglected. This is because the effects of this zone were observed in a simulation run only above $1000 \mathrm{~K}$, and exact simulation at such high temperatures was difficult without consideration on annihilation of defects. The simulatedspectrum agreed with the experimental result with the values $C_{\mathrm{t}}=1.26 \times 10^{26} \mathrm{~m}^{-3}(0.2$ at.\%) and $E_{\mathrm{det}}=1.83 \mathrm{eV}$. Here, the distribution of traps was assumed to be uniform. The binding energy $E_{\text {bin }}$ was evaluated to be $E_{\text {bin }}=1.44 \mathrm{eV}$ by assuming $E_{\text {bin }}=E_{\text {det }}-E_{\mathrm{d}}$ and $E_{\mathrm{d}}=0.39 \mathrm{eV}$ [20]. As shown in previous papers $[11,15]$, various types of defects with different $E_{\operatorname{det}}$ were present in the n-irradiated specimens. Hence, $1.83 \mathrm{eV}$ should be considered as the average value for several different types of traps. In addition, this value was obtained with several assumptions, as mentioned above. A more detailed analysis is required to determine exact values of $E_{\text {det }}$ for each type of traps.

\subsection{Correlation between concentrations of solute and trapped $D$ in ion-irradiated W}

As described in [18], the thickness of the damaged zone created by irradiation of $20 \mathrm{MeV}$ W self-ions was ca. $2 \mu \mathrm{m}$, and the accumulation of $\mathrm{D}$ by exposure to $\mathrm{D}_{2}$ gas was observed only in the damaged zone. Desorption spectra are also given in [18].

The correlation of $F_{\mathrm{D}-\text { trap }}$ at the damage peaks measured using NRA with $T_{\mathrm{ex}}$ and $P$ is shown Fig. 2. Because no significant difference was observed between recrystallized and ITERgrade $\mathrm{W}$, the data for these two types of specimens are indicated by the same symbols. At $P=$ $100 \mathrm{kPa}, F_{\mathrm{D} \text {-trap }}$ was 0.5 at.\% at $673 \mathrm{~K}$, and it decreased gradually with an increase in $T_{\text {ex }}$. The D concentration at $1.2 \mathrm{kPa}$ was clearly lower than that at $100 \mathrm{kPa}$, as shown in this figure. This observation indicates that a local equilibrium between trapping and detrapping was established, and consequently $\theta_{\mathrm{t}}$ was dependent on $C_{\mathrm{SS}}$ at $T_{\mathrm{ex}} \geq 673 \mathrm{~K}$. Eq. (1) can be modified as

$$
\theta_{\mathrm{t}}=\frac{\left(\frac{C_{\mathrm{SS}}}{C_{\mathrm{L}}}\right) \exp \left(\frac{E_{\mathrm{bin}}}{k T_{\mathrm{ex}}}\right)}{1+\left(\frac{C_{\mathrm{SS}}}{C_{\mathrm{L}}}\right) \exp \left(\frac{E_{\mathrm{bin}}}{k T_{\mathrm{ex}}}\right)}
$$

where $C_{\mathrm{SS}}=k_{0} \exp \left(-E_{\mathrm{S}} / k T_{\mathrm{ex}}\right) P^{1 / 2}$. Here, $F_{\mathrm{D}-\text { trap }}($ at. $\%)=C_{\mathrm{t}} \theta_{\mathrm{t}} / C_{\mathrm{W}} \times 100$ where $C_{\mathrm{W}}$ is the concentration of $\mathrm{W}$ atoms. The dependence of $F_{\mathrm{D}-\text { trap }}$ on $T_{\mathrm{ex}}$ and $P$ at different $E_{\text {bin }}$ was evaluated 
by assuming $C_{\mathrm{t}}=3.2 \times 10^{26} \mathrm{~m}^{-3}(0.5$ at. $\%)$ and $E_{\mathrm{S}}=1.04 \mathrm{eV}$ [20]. As indicated by solid and dashed lines in this figure, the difference in $F_{\mathrm{D}-\text { trap }}$ between 100 and $1.2 \mathrm{kPa}$ was reproduced at $E_{\text {bin }}=1.4 \mathrm{eV}$. This value is consistent with that of $E_{\text {bin }}$ determined for the n-irradiated specimen from $E_{\text {det }}$ in spite of the several assumptions in the TMAP4 calculation.

\subsection{Trap concentration at high damage level}

The correlation between $F_{\mathrm{D} \text {-trap }}$ at the damage peaks and damage level in the ion-irradiated specimens after exposure to D neutrals at $403 \mathrm{~K}$ is shown in Fig. 3. No significant increase in $F_{\text {D-trap }}$ with damage level was observed under the present conditions. According to Roth and Schmid [8] who summarized the correlation between trap concentration and damage level at $<1$ dpa, trap concentration ceases to increase at a damage level of ca. 0.4 dpa and a trap concentration of ca. $7.6-8.8 \times 10^{26} \mathrm{~m}^{-3}(1.2-1.4$ at.\%). The observations in this study agree with this tendency.

\subsection{Release of trapped $D$ at constant temperature}

Fig. 4 shows depth profile of D in the specimen irradiated with $20 \mathrm{MeV} \mathrm{W}$ ions to $0.5 \mathrm{dpa}$ and exposed to $\mathrm{D}_{2}$ gas together with that after heating in a vacuum and under $\mathrm{H}_{2}$ gas atmosphere. Slight reduction in $F_{\mathrm{D} \text {-trap }}$ was observed after heating in a vacuum, and this observation is consistent with that of Tsukatani et al. [7]. It should be noted that $F_{\text {D-trap }}$ after heating under $\mathrm{H}_{2}$ gas atmosphere was smaller than that after heating in a vacuum by a factor of 40 ; the release of $D$ was strongly enhanced under the presence of $\mathrm{H}$.

\section{Discussion}

The clear correlation between $\mathrm{D}_{2}$ gas pressure and $F_{\mathrm{D} \text {-trap }}$ shown in Fig. 2 indicates that $\theta_{\mathrm{t}}$ is dependent on $C_{\mathrm{SS}}$ at $T_{\mathrm{ex}} \geq 673 \mathrm{~K}$. Hence, the different temperature dependences of $F_{\mathrm{D} \text {-trap }}$ in damaged $\mathrm{W}$ reported in the literature $[3-6,15]$ can be ascribed, at least in part, to variation of $C_{\mathrm{SS}}$ under different experimental conditions. Because $C_{\mathrm{SS}}$ under plasma exposure is determined by incident and recycling flux, $\theta_{\mathrm{t}}$ increases with an increase in $\phi_{\mathrm{in}}$ and a decrease in $k_{\mathrm{r}}$. The temperature dependence of $\theta_{\mathrm{t}}$ was evaluated with Eq. (1) and the correlation $C_{\mathrm{SS}-\mathrm{S}}=\left(\alpha \phi_{\mathrm{in}} / k_{\mathrm{r}}\right)^{1 / 2}$ 
under two different surface conditions, as shown in Fig. 5. Here, $E_{\text {bin }}$ was determined to be $1.4 \mathrm{eV}$. The values of $k_{\mathrm{r}}$ reported by Anderl et al. [22], $k_{\mathrm{r}-\text { Anderl }}$, was used in one case. In the other case, $k_{\mathrm{r}}$ was assumed to be larger than $k_{\mathrm{r} \text {-Anderl }}$ by $10^{6}$. Note that $k_{\mathrm{r}-\text { Anderl }} \times 10^{6}$ is still far smaller than the value for a clean surface [8]. It is clearly shown in this figure that $\theta_{\mathrm{t}}$ at high temperatures, e.g. $773 \mathrm{~K}$, sensitively varies in accordance with $\alpha \phi_{\mathrm{in}}$ and $k_{\mathrm{r}}$, whereas it is close to unity at $T_{\mathrm{ex}} \leq 550$ $\mathrm{K}$ under all conditions examined. Whyte et al. [17] evaluated the amount of trapped tritium under ITER-relevant conditions with a smaller value of $E_{\mathrm{det}}(1.5 \mathrm{eV})$ and reported similar dependence on incident flux and temperature.

The development of techniques for removing $\mathrm{T}$ is an important issue. The removal of $\mathrm{D}$ in ion-irradiated $\mathrm{W}$ by heating in a vacuum was possible as reported by Tsukatani et al. [7] and shown in Fig. 4. However, the removal of $\mathrm{T}$ from thick $\mathrm{n}$-irradiated $\mathrm{W}$ would be much more difficult. Fig. 6 shows the change in the average fraction of $\mathrm{T}$ with time at different $\mathrm{W}$ thickness evaluated using the TMAP4 program. The trap concentration, $C_{\mathrm{t}}$, was assumed to be $1.26 \times 10^{26}$ $\mathrm{m}^{-3}\left(0.2\right.$ at.\%) and uniform throughout the thickness of materials, and $E_{\mathrm{det}}$ were adjusted to 1.8 $\mathrm{eV}$. The thickness of the material was assumed to be 600 or $2 \mu \mathrm{m}$. The former was selected as a typical value for armor layers of first walls, and the latter was selected as a typical thickness of the damaged zone created by ion-irradiation. The initial value of $\theta_{\mathrm{t}}$ was adjusted to unity throughout the thickness; i.e., T was distributed at traps uniformly up to full occupancy. If the material was thin $(2 \mu \mathrm{m})$, the average $\mathrm{T}$ fraction throughout the thickness significantly decreased with time at $673 \mathrm{~K}$, as previously mentioned. However, in the case of a thick material $(600 \mu \mathrm{m})$, no significant reduction in the average $\mathrm{T}$ fraction was observed at $673 \mathrm{~K}$ even after heating for 10 h. At $973 \mathrm{~K}$, the $\mathrm{T}$ fraction clearly decreased, but $40 \%$ of $\mathrm{T}$ still remained after heating for $10 \mathrm{~h}$. These observations indicate that the removal of $\mathrm{T}$ by baking in a vacuum at moderate temperatures $(\leq 673 \mathrm{~K})$ is not very effective if $\mathrm{T}$ deeply penetrates into n-irradiated W (e.g., several hundred micrometers). As described in Section 2, $D_{\text {eff }}$ of $\mathrm{H}$ isotopes in damaged $\mathrm{W}$ is controlled by trapping-detrapping processes. Hence, $D_{\text {eff }}$ of $\mathrm{T}$ could drastically increase if the majority of traps are occupied by $\mathrm{H}$ or D. Indeed, Fig. 4 clearly indicates the significant enhancement of $\mathrm{D}$ release under the presence of excess $\mathrm{H}$; one of $\mathrm{H}$ atoms in a solution state can immediately occupies an empty trap produced by D detrapping and consequently prevents re- 
trapping of D. A similar enhancement of T release under the presence of H or D is also expected, and experiments for confirmation are currently under preparation.

The correlation between $F_{\mathrm{D} \text {-trap }}$ and damage level shown in Fig. 3 suggests that a severe damage level without transmutation does not increase the T inventory significantly. The next step is to understand the effects of transmutation and the synergistic effects of transmutation and severe damage levels.

\section{Conclusions}

(1) Deep penetration of D up to a depth of 50-100 $\mu \mathrm{m}$ was observed by exposing a n-irradiated $\mathrm{W}$ specimen to D plasma at $773 \mathrm{~K}$. Desorption of D continued to temperature higher than $1173 \mathrm{~K}$ because of the long diffusion distance under the trapping effects. The average detrapping energy was evaluated to be ca. $1.8 \mathrm{eV}$.

(2) At high temperatures $(\geq 673 \mathrm{~K})$, the fraction of occupied traps was clearly dependent on the concentration of D in a solid solution state. This observation indicated that accumulation of $\mathrm{H}$ isotopes to a high concentration is possible even at a high temperature if the incident flux from plasma is relatively high and the surface recombination rate constant is relatively small.

(3) A numerical simulation for thick n-irradiated $\mathrm{W}$ showed a strong retardation of $\mathrm{H}$ isotope release due to trapping effects. Baking in a vacuum at moderate temperatures $(\leq 673 \mathrm{~K})$ could not be very effective in removal of T deeply penetrating into the bulk of n-irradiated W.

(4) The release of D from damaged $\mathrm{W}$ was significantly pronounced under the presence of $\mathrm{H}$ at $673 \mathrm{~K}$. This enhanced release was ascribed, at least in part, to increase in the effective diffusion coefficient of $\mathrm{D}$ by filling traps with $\mathrm{H}$. The release of $\mathrm{T}$ could also be enhanced under the presence of $\mathrm{H}$ and/or D.

(5) Irradiation of $\mathrm{W}$ by self-ions to $50 \mathrm{dpa}$ at room temperature or $573 \mathrm{~K}$ resulted in the accumulation of $\mathrm{D}$ in the damaged zone up to $0.5-1$ at.\%. These values are comparable with the trap concentration observed at damage levels below 1 dpa [8].

\section{Acknowledgements}

This work was supported by the Japan-US joint research project TITAN, Kakenhi on Priority Areas, 476, Tritium for Fusion, from MEXT, Japan and the Collaboration Research 
Programs of National Institute of Fusion Science, Japan (NIFS10KUMR004 and NIFS11KEMF018). The authors thank to Dr. T. Yamanishi and Dr. K. Isobe in Japan Atomic Energy Agency for the supply of recrystallized and ITER-grade W specimens.

\section{References}

[1] M. Fukumoto, H. Kashiwagi, Y. Ohtsuka, Y. Ueda, M. Taniguchi, T. Inoue, K. Sakamoto, J. Yagyu, T. Arai, I. Takagi, T. Kawamura, J. Nucl. Mater. 390-391 (2009) 572-575.

[2] B. Tyburska, V. Kh. Alimov, O. V. Ogorodnikova, K. Schmid, K. Ertl, J. Nucl. Mater. 395 (2009) 150.

[3] W. R. Wampler, R. P. Doerner, Nucl. Fusion 49 (2009) 115023.

[4] G. M. Wright, M. Mayer, K. Etrl, G. de Saint-Aubin, J. Rapp, Nucl. Fusion 50 (2010) 075006.

[5] O. V. Ogorodnikova, B. Tyburska, V. Kh. Alimov, K. Ertl, J. Nucl. Mater. 415 (2011) S661.

[6] B. Tyburska, V. Kh. Alimov, O. V. Ogorodnikova, K. Ertl, K. Schmid, J. Roth, J. Nucl. Mater. 415 (2011) S680.

[7] K. Tsukatani, Y. Ueda, K. Tanimoto, H. T. Lee, Y. Ohtsuka, M. Taniguchi, T. Inoue, K. Sakamoto, I. Takagi, N. Yoshida, Fusion Sci. Technol. 60 (2011) 1543.

[8] J. Roth, K. Schmid, Phys. Scr., T145 (2011) 014031.

[9] V. Kh. Alimov, B. Tyburska-Püschel, Y. Hatano, J. Roth, K. Isobe, M. Matsuyama, T. Yamanishi, J. Nucl. Mater. 420 (2012) 370.

[10] M. H. J. 't Hoen, B. Tyburska-Püschel, K. Etrl, M. Mayer, J. Rapp, A. W. Kleyn, P. A. Zeijlmans van Emmichoven, Nucl. Fusion 52 (2012) 023008.

[11] M. Shimada, Y. Hatano, P. Calderoni, T. Oda, Y. Oya, M. Sokolov, K. Zhang, G. Cao, R. Kolasinski, J. P. Sharpe, J. Nucl. Mater. 415 (2011) S667.

[12] T. Oda, M. Shimada, K. Zhang, P. Calderoni, Y. Oya, M. Sokolov, R. Kolasinski, J. P. Sharpe, Y. Hatano, Fusion Sci. Technol. 60 (2011) 1455.

[13] Y. Oya, M. Shimada, M. Kobayashi, T. Oda, M. Hara, H. Watanabe, Y. Hatano, P. Calderoni, K. Okuno, Phys. Scr. T145 (2011) 014050. 
[14] M. Shimada, Y. Hatano, Y. Oya, T. Oda, M. Hara, G. Cao, M. Kobayashi, M. Sokolov, H. Watanabe, B. Tyburska-Püschel, Y. Ueda, P. Calderoni, K. Okuno, Fusion Eng. Design 87 (2012) 1166.

[15] M. Shimada, G. Cao, Y. Hatano, T. Oda, Y. Oya, M. Hara, P. Calderoni, Phys. Scr. T145 (2011) 014051.

[16] R. Gibala, A. J. Kumnick, Hydrogen trapping in iron and steels, in: R. Gibala, R. F. Hehemann (Eds.), Hydrogen Embrittlement and Stress Corrosion Cracking, American Society for Metals, Metal Park, Ohio, 1984, pp. 61-77.

[17] D. G. Whyte, J. Nucl. Mater. 390-391 (2009) 911.

[18] V. Kh. Alimov, Y. Hatano, K. Sugiyama, J. Roth, B. Tyburska-Püschel, J. Dorner, J. Shi, M. Matsuyama, J. Nucl. Mater. in press.

[19] R. A. Oriani, Acta Metall. 18 (1970) 147.

[20] R. Frauenfelder, J. Vac. Sci. Technol. 6 (1969) 388.

[21] G. R. Longhurst, D. F. Holland, J. L. Jones, B. J. Merrill, TMAP4 User's Manual, EGGFSP-10315, DOI: 10.2172/7205576.

[22] J. F. Ziegler, http://www.srim.org/.

[23] R. A. Anderl, D. F. Holland, G. R. Longhurst, R. J. Pawelko, C. L. Trybus, C. H. Sellers, Fusion Technol. 21 (1992) 745. 


\section{Figure captions}

Fig. 1 TDS spectra of deuterium from n-irradiated and non-irradiated W (solid lines) after exposure to plasma at $773 \mathrm{~K}$. Dashed and dotted lines are results of simulation using the TMAP4 program with different $E_{\text {det }}$. Trap concentration and thickness of damaged W were assumed to be $1.3 \times 10^{26} \mathrm{~m}^{-3}(0.2$ at. $\%)$ and $100 \mu \mathrm{m}$, respectively. For comparison, TDS spectrum from W specimen irradiated to $50 \mathrm{dpa}$ with $4.8 \mathrm{MeV} \mathrm{W}$ ions at $573 \mathrm{~K}$ and exposed to D neutrals at $403 \mathrm{~K}$ is also shown. The rate of temperature ramp was $0.167 \mathrm{~K} \mathrm{~s}^{-1}\left(10 \mathrm{~K} \mathrm{~min}^{-1}\right)$ for the $\mathrm{n}$ - and nonirradiated specimens and $0.5 \mathrm{~K} \mathrm{~s}^{-1}$ for the ion-irradiated specimens.

Fig. 2 Correlation between $F_{\text {D-trap }}$ at damage peak and $T_{\text {ex }}$ in $\mathrm{W}$ specimens irradiated with 20 $\mathrm{MeV} \mathrm{W}$ ions to $0.5 \mathrm{dpa}$ after exposure to $\mathrm{D}_{2}$ gas at $P=1.2 \mathrm{kPa}$ (filled circles) or $100 \mathrm{kPa}$ (open squares). Solid and dashed lines are evaluated with Eq. (4) with H solubility reported by Frauenfelder [20] and $E_{\text {bin }}=1.4 \mathrm{eV}$.

Fig. 3 Correlation between damage level and $F_{\mathrm{D} \text {-trap }}$ at damage peak in $\mathrm{W}$ specimens irradiated at room temperature and $573 \mathrm{~K}$ with $\mathrm{W}$ ions of $20 \mathrm{MeV}(0.5 \mathrm{dpa})$ and $4.8 \mathrm{MeV}$ (other damage levels) and exposed to D neutrals at $403 \mathrm{~K}$.

Fig. 4 Damage and D depth profiles in recrystallized W irradiated with $20 \mathrm{MeV}$ W ions to 0.5 dpa. The $\mathrm{D}$ profiles were measured after exposure to $\mathrm{D}_{2}$ gas at $673 \mathrm{~K}$ and $0.1 \mathrm{MPa}$, and subsequent heating in a vacuum or under $\mathrm{H}_{2}$ atmosphere at $673 \mathrm{~K}$ for $10 \mathrm{~h}$.

Fig. 5 Dependence of $\theta_{\mathrm{t}}$ on $T_{\mathrm{ex}}, \alpha \phi_{\text {in }}$ and $k_{\mathrm{r}}$ at $E_{\text {bin }}=1.4 \mathrm{eV}$ evaluated from Eq. (1) and correlation $C_{\text {SS-S }}=\left(\alpha \phi_{\text {in }} / k_{\mathrm{r}}\right)^{1 / 2} ; k_{\mathrm{r} \text {-Anderl }}$ and $k_{\mathrm{r} \text {-Anderl }} \times 10^{6}$ indicate the value of $k_{\mathrm{r}}$ reported in [23] and that larger than $k_{\mathrm{r}-\text { Anderl }}$ by a factor of $10^{6}$, respectively.

Fig. 6 Change in average $\mathrm{T}$ fraction throughout the thickness of n-irradiated $\mathrm{W}$ evaluated by using the TMAP4 program. The thickness of $\mathrm{W}$ was adjusted to 2 or $600 \mu \mathrm{m}$. Trap concentration was assumed to be uniform at $1.26 \times 10^{26} \mathrm{~m}^{-3}(0.2$ at. $\%)$ throughout the thickness. The initial $\theta_{\mathrm{t}}$ and $E_{\text {det }}$ were adjusted to unity and $1.8 \mathrm{eV}$, respectively. 


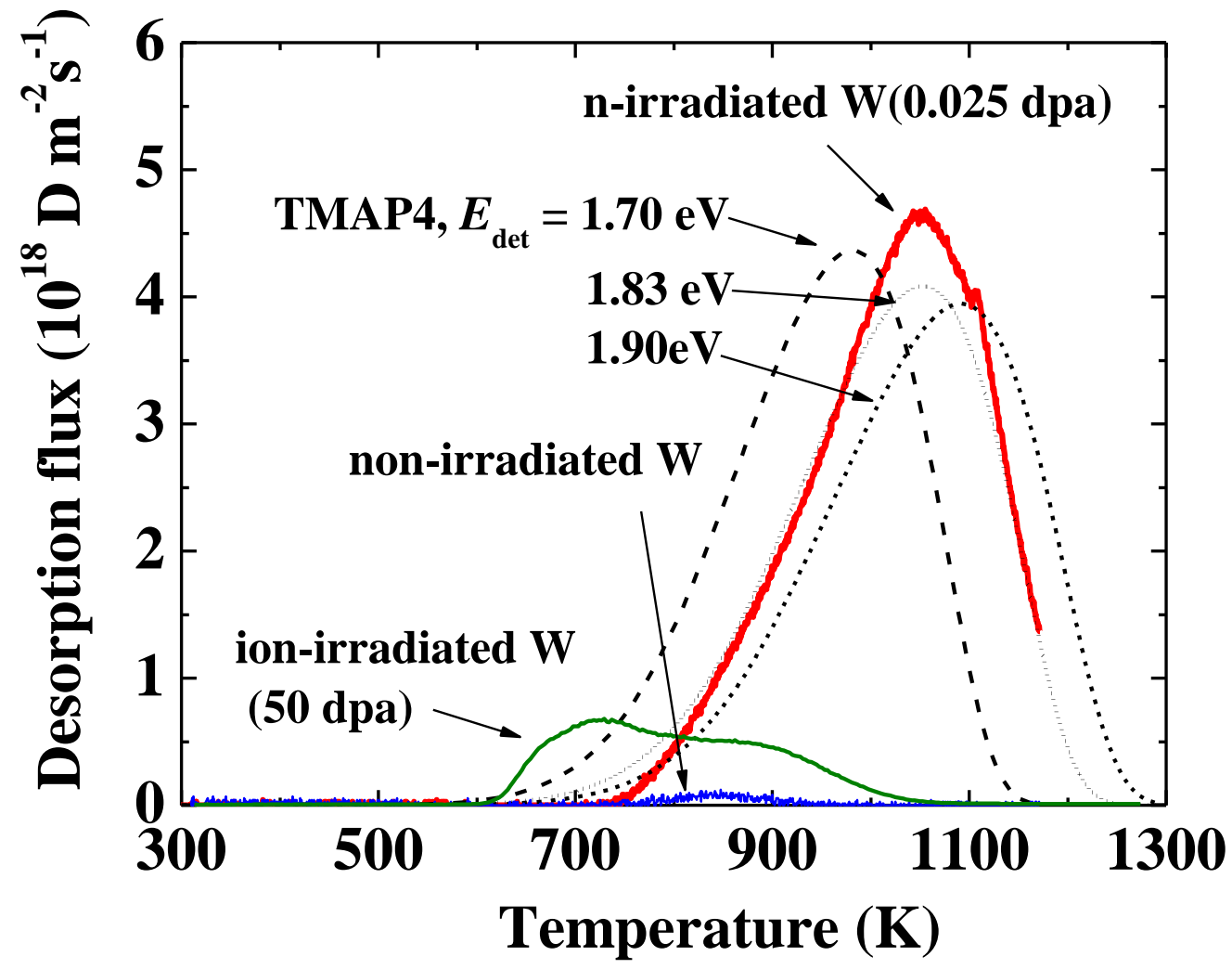

Fig. 1 TDS spectra of deuterium from n-irradiated and non-irradiated W (solid lines) after exposure to plasma at $773 \mathrm{~K}$. Dashed and dotted lines are results of simulation using the TMAP4 program with different $E_{\text {det }}$. Trap concentration and thickness of damaged W were assumed to be $1.3 \times 10^{26} \mathrm{~m}^{-3}(0.2$ at. \%) and $100 \mu \mathrm{m}$, respectively. For comparison, TDS spectrum from W specimen irradiated to $50 \mathrm{dpa}$ with $4.8 \mathrm{MeV} \mathrm{W}$ ions at $573 \mathrm{~K}$ and exposed to D neutrals at $403 \mathrm{~K}$ is also shown. The rate of temperature ramp was $0.167 \mathrm{~K} \mathrm{~s}^{-1}\left(10 \mathrm{~K} \mathrm{~min}^{-1}\right)$ for the $\mathrm{n}$ - and nonirradiated specimens and $0.5 \mathrm{~K} \mathrm{~s}^{-1}$ for the ion-irradiated specimens. 


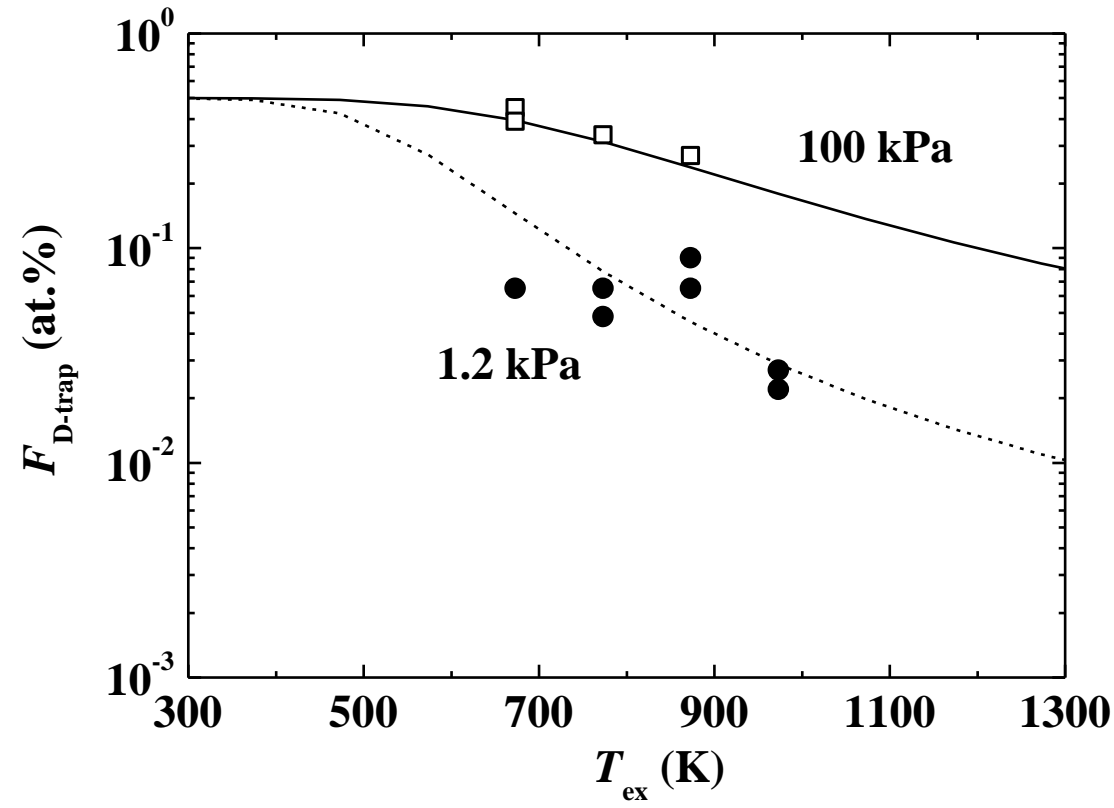

Fig. 2 Correlation between $F_{\mathrm{D} \text {-trap }}$ at damage peak and $T_{\text {ex }}$ in W specimens irradiated with $20 \mathrm{MeV} \mathrm{W}$ ions to $0.5 \mathrm{dpa}$ after exposure to $\mathrm{D}_{2}$ gas at $P=1.2 \mathrm{kPa}$ (filled circles) or 100 $\mathrm{kPa}$ (open squares). Solid and dashed lines are evaluated with Eq. (4) with H solubility reported by Frauenfelder [20] and $E_{\text {bin }}=1.4 \mathrm{eV}$. 


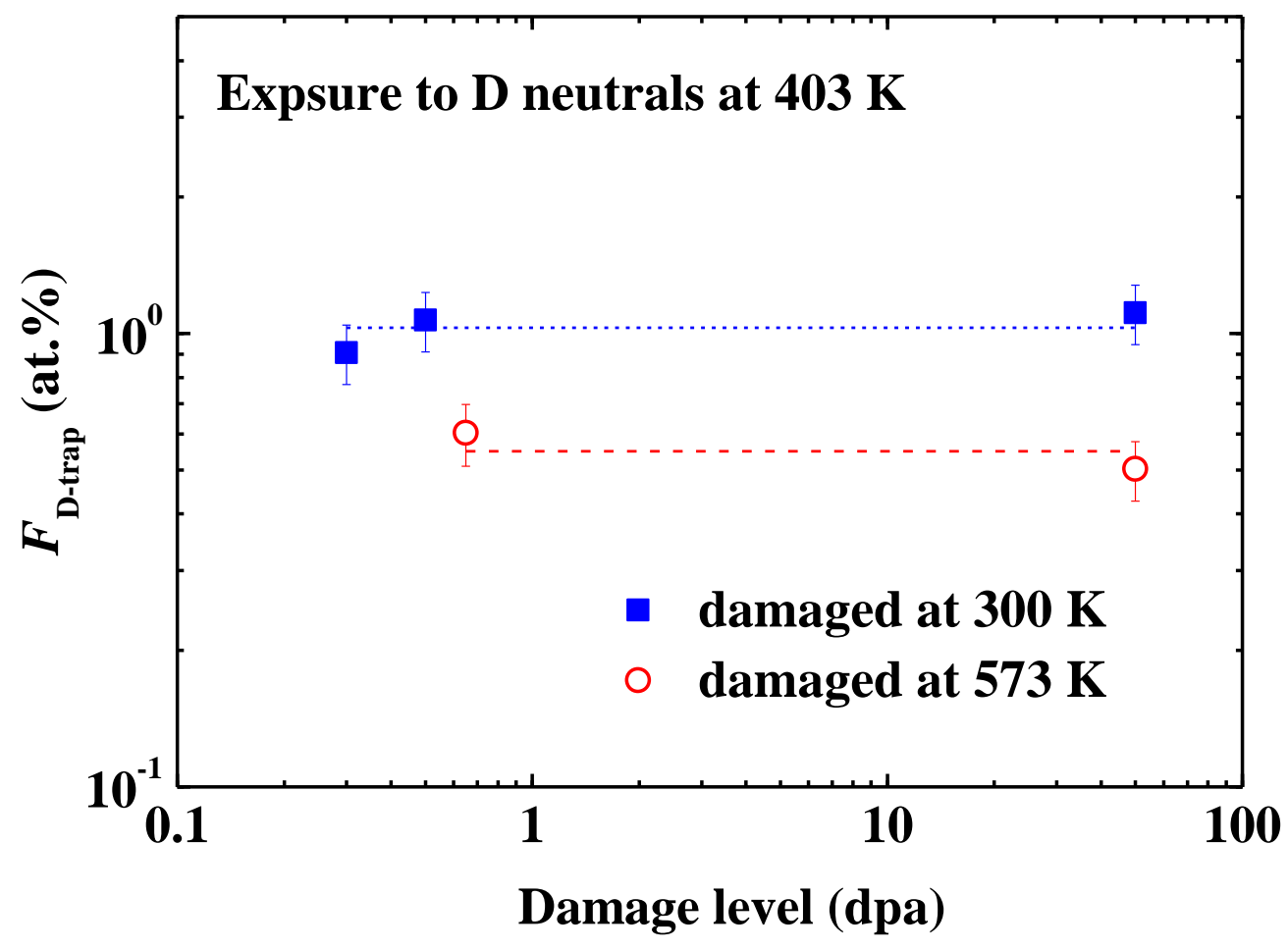

Fig. 3 Correlation between damage level and $F_{\mathrm{D}-\text { trap }}$ at damage peak in $\mathrm{W}$ specimens irradiated at room temperature and $573 \mathrm{~K}$ with $\mathrm{W}$ ions of $20 \mathrm{MeV}(0.5 \mathrm{dpa})$ and 4.8 $\mathrm{MeV}$ (other damage levels) and exposed to D neutrals at $403 \mathrm{~K}$. 


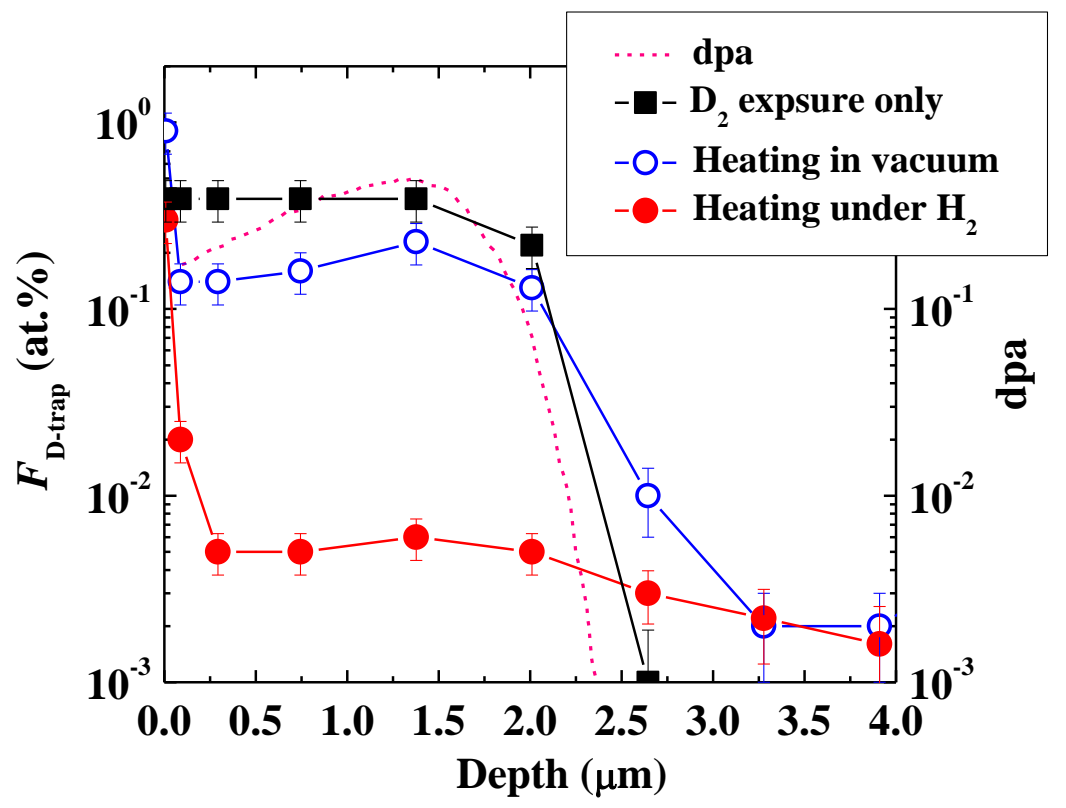

Fig. 4 Damage and D depth profiles in recrystallized W irradiated with $20 \mathrm{MeV}$ $\mathrm{W}$ ions to $0.5 \mathrm{dpa}$. The $\mathrm{D}$ profiles were measured after exposure to $\mathrm{D}_{2}$ gas at 673 $\mathrm{K}$ and $0.1 \mathrm{MPa}$, and subsequent heating in a vacuum or under $\mathrm{H}_{2}$ atmosphere at $673 \mathrm{~K}$ for $10 \mathrm{~h}$. 


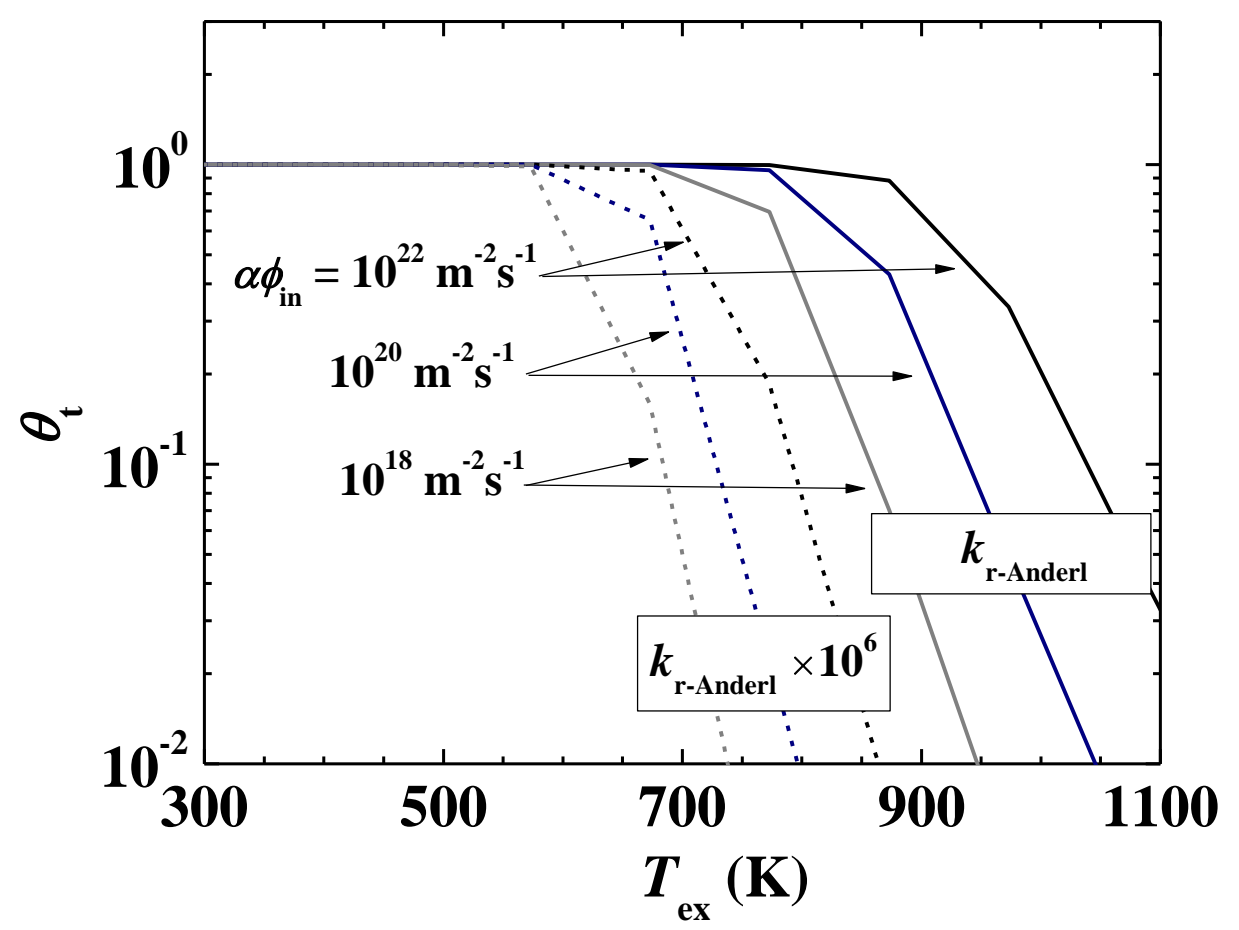

Fig. 5 Dependence of $\theta_{\mathrm{t}}$ on $T_{\mathrm{ex}}, \alpha \phi_{\mathrm{in}}$ and $k_{\mathrm{r}}$ at $E_{\text {bin }}=1.4 \mathrm{eV}$ evaluated from Eq. (1) and correlation $C_{\mathrm{SS}-\mathrm{S}}=\left(\alpha \phi_{\mathrm{in}} / k_{\mathrm{r}}\right)^{1 / 2} ; k_{\mathrm{r} \text {-Anderl }}$ and $k_{\mathrm{r} \text {-Anderl }} \times 10^{6}$ indicate the value of $k_{\mathrm{r}}$ reported in [23] and that larger than $k_{\mathrm{r} \text {-Anderl }}$ by a factor of $10^{6}$, respectively. 


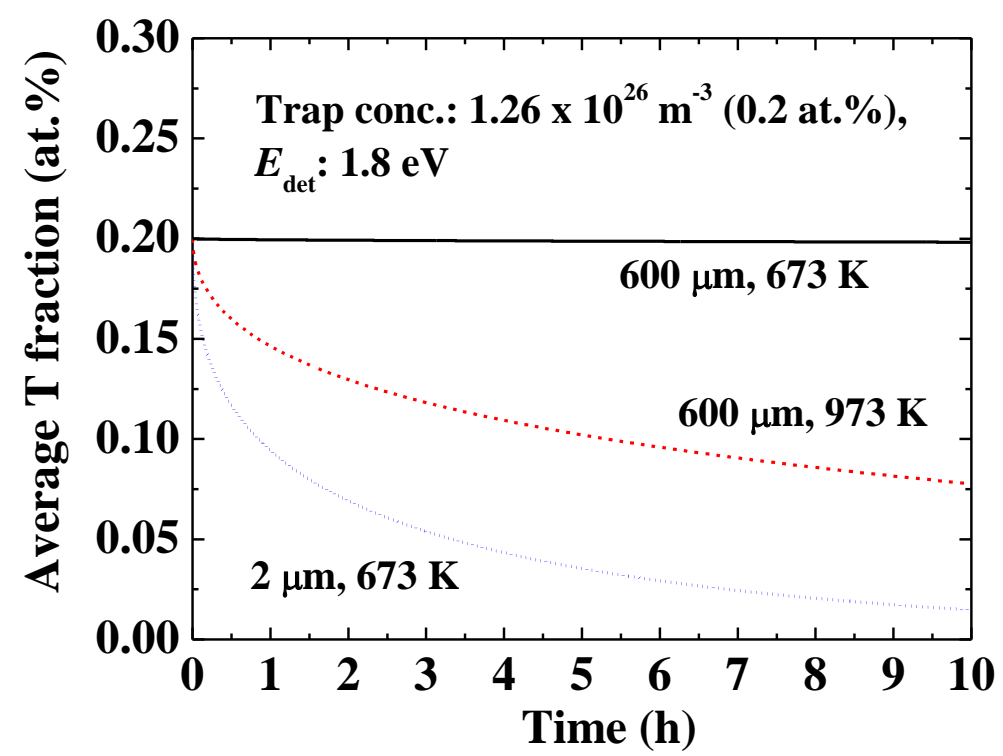

Fig. 6 Change in average $\mathrm{T}$ fraction throughout the thickness of $\mathrm{n}$-irradiated $\mathrm{W}$ evaluated by using the TMAP4 program. The thickness of $\mathrm{W}$ was adjusted to 2 or $600 \mu \mathrm{m}$. Trap concentration was assumed to be uniform at $1.26 \times 10^{26} \mathrm{~m}^{-3}$ ( 0.2 at.\%) throughout the thickness. The initial $\theta_{\mathrm{t}}$ and $E_{\text {det }}$ were adjusted to unity and $1.8 \mathrm{eV}$, respectively. 